Article

\title{
Design Thinking Methodology to Achieve Household Engagement in Urban Water Sustainability in the City of Huelva (Andalusia)
}

\author{
Gustavo Bermejo-Martín (D) and Carlos Rodríguez-Monroy *(D) \\ Department of Industrial Organization, Business Administration and Statistics, ETS Ingenieros Industriales, \\ Universidad Politécnica de Madrid (UPM), 28040 Madrid, Spain; gustavo.bermejo.martin@gmail.com \\ * Correspondence: carlos.rodriguez@upm.es
}

Received: 27 May 2020; Accepted: 6 July 2020; Published: 8 July 2020

\begin{abstract}
To advance to water sensitive cities (WSC) it will be necessary to achieve the commitment of the citizens, involving them in this transition. Citizen participation is considered essential, and one of the possible approaches to achieve this is through Design Thinking (DT), a human-centered methodology that allows creating a framework to develop the hydrosocial contract. The Suez group proposed the challenge of collecting initiatives to achieve more efficient use of urban water in homes, by conducting a pilot in one of its investee companies, Aguas de Huelva. Our research proposal, selected by the Suez group, to achieve greater engagement of households regarding efficient water use, was to develop a web-based prototype applying DT methodologies, which would allow us to generate new messages and meanings regarding water, producing an innovation of meaning that would enable tracking the progress of the results. This article describes the approved framework to carry out the pilot experience in the homes of the city of Huelva in Andalusia, Spain.
\end{abstract}

Keywords: Design Thinking; hydrosocial contract; human smart city; web-based prototype; engagement; design for behavior; ICT technologies; household; sustainable urban water management; social innovation

\section{Introduction}

This article will focus on urban water as a critical element in intermediary cities. The "entire urban water cycle" should be considered, and water integrated into the design of solutions for the sustainable development of cities. This paper aims to propose a framework that reflects the central role of citizens in the design of these solutions and explains how it relates to water, expressing itself through the private behavior of households.

Previously, we made an x-ray of how and to what extent investments in water had been taken into account for integrated sustainable urban development and the needs of citizens, from the different public administrations, analyzing the approved Integrated Sustainable Urban Development Strategy (ISUDS) plans and endowed with funds in the first round of financing in the Andalusian region [1]. The citizens are the main actors through their participation in the elaboration of the ISUDS. In a way, these plans are expressions of citizens' public behavior concerning water, their values, and their needs. People's role as active agents is crucial in the good achievement of sustainability policies, and their needs should be met.

This first analysis should be completed by crossing the results of this previous research on the public behavior of citizens concerning their private behavior in the use of water in households. Private behavior would measure citizens' social needs [2], placing a particular emphasis on real habits of comfort and cleanliness [3]. This would give us a picture of the common patterns and coherences between these two spheres of the citizen, public, and private [4]. To carry out such research, it would 
be necessary to count on each city's water company with ISUDS, which is the entity that interacts most directly and most frequently with citizens. It would be interesting to have Information and Communication Technologies (ICT) facilitators as a measuring tool and means of education on the efficient use of water in the home, as a first step to initiate a transition where water will play an essential role in the sustainability of the city. The purpose of this paper is to propose applying Design Thinking (DT) methodology to achieve household engagement in urban water sustainability.

To develop it, we take the Huelva city case, which has an ISUDS analyzed in [1]. Huelva is an intermediary city (between 50,000 and one million inhabitants) in Andalucía (Spain). It presents practically no population growth. One of the challenges of this type of city will be to avoid the migration of young people to larger cities, the aging of the population, and the loss of economic dynamism. It has four main urban challenges that affect water, demographic stagnation, social diversity, climate change, and unstable and unpredictable water social needs [5].

Water in Huelva has a crucial impact on sustainability and its relationship (nexus) with other urban assets such as energy and food. The value of an intermediary city such as Huelva stands out as a condition of intersection spaces between the rural and the urban habitats [6], where the water, energy, and food nexus have a significant influence [7]. This type of urban pole has a high impact on how supply chains of products are established, from rural areas to the coast, to metropolises and peripheries and, therefore, are the local patterns of consumption and production that are decisive for achieving sustainable urban development.

The ISUDS of Huelva does not collect actions that treat the clear relationship between the water-food nexus. It draws attention to an agricultural region such as Huelva. There is a disconnection between the urban and agricultural characters, as two separate spheres in the city's management. Plans to reduce the pollution that agriculture can produce on surface waters or aquifers are needed. This is one of the future social-ecological challenges of urban and peri-urban agriculture (UPA) in Huelva. As explained in [8], highlighting UPA depends strongly on the effective recycling of wastewater and water-efficient use by citizens. On the contrary, water quality depends on nutrients recycling and other residues of agricultural production. Other similar insights into these socio-ecological production systems along urban value chains is found in [8].

The population of Huelva does not increase due to migration from the rural environment, and it does not have pressure on scarce land and water resources, as occurs in other mid-sized cities [9]. UPA should play an essential role in balancing landscape transformation processes, income generation (tourism, agricultural products), food security, and recycling waste (pollution). It is needed to broaden citizen literacy about the water-food nexus, and its impact on pollution; additionally, as [9] proposes, new options for non-traditional sources of water and land are needed.

We concluded that Huelva did not take into account a more significant water presence as a focus of its ISUDS [1]. There is a lack of a more significant appreciation of water by citizens. Citizen education policies regarding the efficient use of water and its economic and environmental impact on the city's future are crucial to achieving greater sustainable development. Citizen literacy and new sources of water services are vital parts of the framework developed in this paper.

To respond to these challenges, the concept of sustainable development and its management appears, which, applied to water, is mentioned in the scientific literature as Sustainable Urban Water Management (SUWM) [10]. This concept of SUWM is an integral approach to the water challenge in cities. It is related to other concepts such as Water Sensitive City (WSC) or Water Smart City and explains how it relates to water, expressing itself through the so-called hydrosocial contract [11].

The hydrosocial contract [11] is understood as the values and, often, implicit agreements between communities, governments, and businesses on how water can be used. This hydrosocial contract will reflect citizens' practice and behavior in water use within the city and the needs and mechanisms used to satisfy them. 
We believe that in Huelva, it is necessary to move towards a more significant development of the hydrosocial contract, through better education of citizens in aspects related to water that make it more visible and allowing global and connected actions to make the city more sustainable [1].

The problem is that unlike other areas of the world where there is a shortage of water [12], and the citizen can perceive it, it does not occur in Huelva. The city's water reserves could supply households for three years. The main problem is that water remains invisible for some services that citizens receive and this expresses the disconnection of citizens regarding the impact of their actions on the sustainable development of their city. It seems that water is only a problem for the water company, not the city's responsibility. One of the possible solutions to make water more visible, as suggested in [12] for the people living in Jordan, improving people's understanding of an issue guides their actions towards finding and implementing appropriate solutions around water. Furthermore, educational actions on water would also improve citizens' education on the city's environmental sustainability [12]. As reported [13], the main objectives of such activities would be to build trust and improve citizens' understanding of environmental issues.

Moreover, the previous needs are not isolated, but instead, they occur in a specific city context, where the citizen satisfies them or do not depend on the water services that the city implements. According to the needs covered by the services already deployed, depending on the existing hydrosocial contract and the relationship between habitability [14] (aspiration to quality of life level and wellbeing) and sustainability [15] (conservation of resources in the medium and long term) of the citizens, a roadmap can be designed to advance to WSC. For this, it will be necessary to achieve the citizens' commitment (engagement), involving them in this transition.

This is aligned with the more general concept of Human Smart Cities (HSC), which seeks to improve the quality of life of citizens, and where they, and not technology, are the center of urban intelligence [16].

Citizen participation is considered essential, and one of the possible approaches to achieve this is through Design Thinking (DT), a human-centered methodology $[17,18]$. This methodology, combined with other HSC methodologies, allows creating a framework to develop the hydrosocial contract. Among these methodologies, we can also highlight Urban Living Labs (ULL) and Gamification [19], as shown in Figure 1.

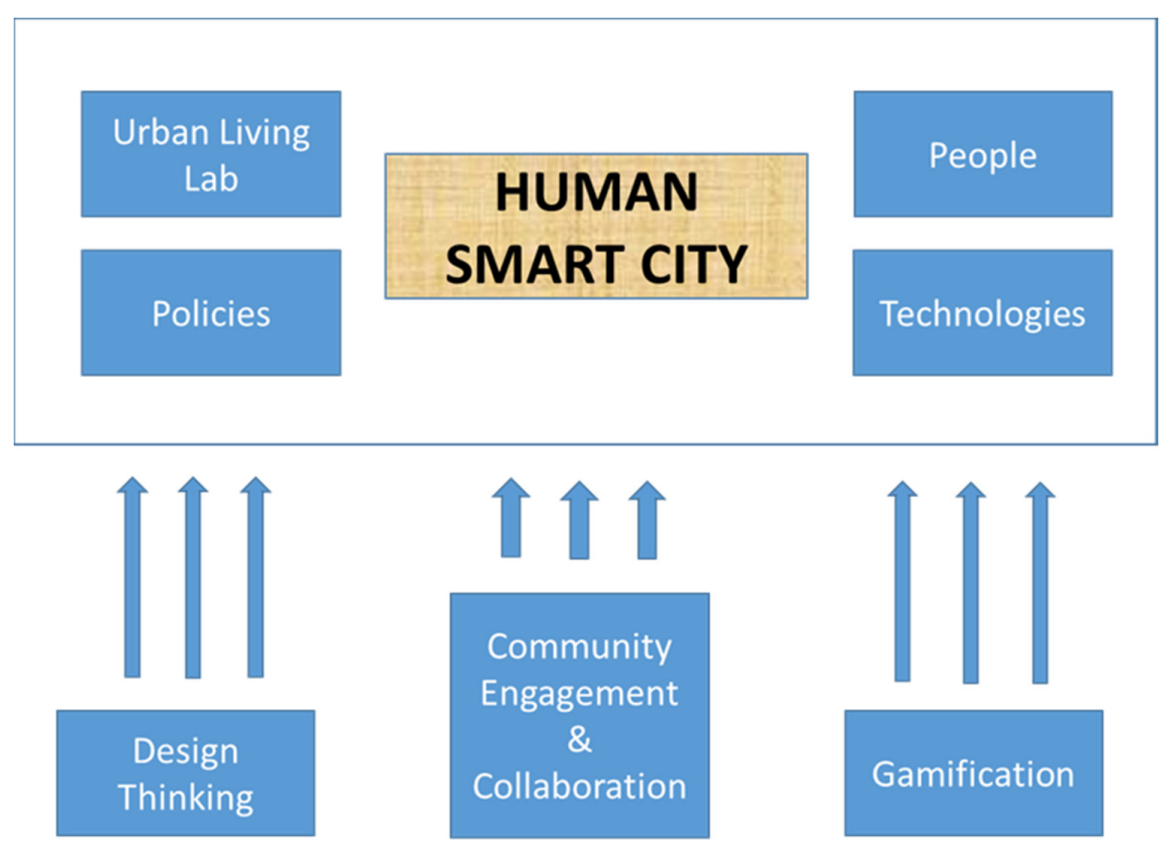

Figure 1. Human Smart Cities (HSC). Methodologies. Adapted from [19]. 
Municipal water services, the direct public responsibility of each city council, are carried out in most Spanish cities through a water utility, which is either entirely private or of mixed public-private ownership. The latter is the case of the water company of the city of Huelva (Andalusia), Aguas de Huelva, where $51 \%$ belongs to the Huelva city council and $49 \%$ belongs to the Suez group [20].

The tool by which this public service is provided is commissioning. Commissioning focuses on the challenges of front-line delivery as opposed to focusing on policy or budgetary levers. Often, commissioning involves engagement with, or delegation to, a third party to undertake a defined task [21]. The government does not provide the service directly. It is an enabler that picks up the needs of citizens and assesses the outcomes delivered by commissioned services. In this case, the commissioner is the utility Aguas de Huelva.

As highlighted [21], the commissioner has two characteristics [21]:

1. "Commissioners should have a clear sense of the needs of a defined population and seek to procure services that match these needs.

2. Commissioners should possess the technical and managerial skills needed to assess the vulnerability and resilience of the services being commissioned."

Therefore, if we analyze the behavior of households in Huelva regarding water use, we will have a photograph of their individual behavior, and therefore, a complementary analysis to that obtained through the analysis of the ISUDS of the city of Huelva. To do this, we needed the collaboration of Aguas de Huelva to access client households and obtain data on the use that these households make of water.

Moreover, Design Thinking encourages end-users, policy designers, central departments, and line agencies to work collaboratively and iteratively [22,23]. There are cases of public service commissioning where the application of DT methodology has improved the implementation of services. A description of its application can be found in [21] for the case of charter schools in the United States.

Additionally, the Suez group proposed the challenge of collecting initiatives to achieve more efficient use of urban water in homes, which was in line with social innovation with other programs carried out by Aguas de Huelva. Social innovation is one of the most critical factors in the Corporate Social Responsibility (CSR) strategy. Social innovation aims to improve citizens' quality of life by maximizing social value, not economic value. This creates a paradox for companies, in line with what was indicated by Altuna et al. [24], especially in the case of water companies, which maximize their income with higher water consumption by citizens. However, at the same time, they must conserve natural sources, the origin of water itself, and its ethical commitment to the community where they provide their service. Therefore, sustainability becomes a critical factor in ensuring the future existence of the water company and citizens' quality of life.

One of the methodologies that best develop social innovation is DT We could highlight that DT delves into the user experience, "of what users experience or develop when accessing and interacting with a product or service" [25]. There is no explicit agreement on the definition of DT, and different interpretations are given [26]. DT would be more like a collection of methods. Among them, we can highlight that "The Design Council introduced the Double Diamond approach [27]. Stanford School developed the five-stage approach [28] and Liedtka and Ogilvie their Designing for Growth approach" [29]. In Hehn et al. [30], some 172 methods in total are identified, of which 59 would be relevant for service innovation. In Table 1, a top-five ranking method used in service firms is shown for every step in the DT process. 
Table 1. Use Ranking Design Thinking (DT) methods. Adapted from [30].

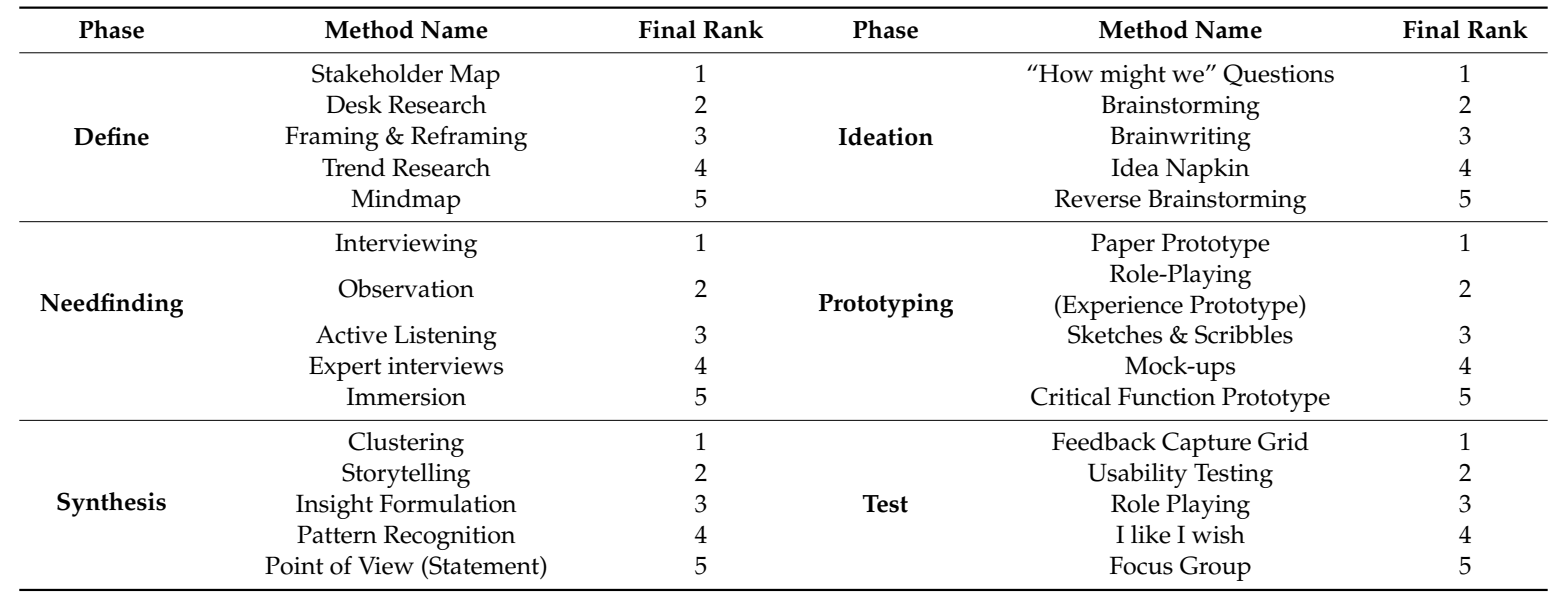

However, not only is there an enormous diversity among DT methods, but there is also a variety of classifications in the phases that make up any DT method. One of the most used is the one that includes five phases with iteration between them [31]: empathize, define, devise, prototype, and test.

Although other authors [32] include the previous stages in three main steps/phases that constitute the iterative (circular) process of DT that seems more appropriate for social innovation:

1. Observation-Inspiration-Synthesis: definition of the problem by iteration; discovery of user needs. Usually through ethnographic techniques.

2. Ideation: search for the solution by generating ideas and selecting the most appropriate ones. This is the creative stage.

3. Implementation (Prototyping-Testing-Communication): Evaluate the proposed solution through the construction of prototypes and the users' engagement in the tests to obtain the necessary feedback to refine the solution.

DT's priorities are visualized in the concept "Three Lenses of Human-Centered Design", which integrates, in each solution reached, uniquely, three key aspects [33]:

1. Desirability: how the market, and in particular users and potential clients, connect emotionally with the solution.

2. Viability: relative to the business model, in financial aspects, and market reach.

3. Feasibility: regarding the technological potential and the technical implementation of the solution.

Furthermore, Shapira et al. [26] added a new key aspect: the solution must be sustainable. In the same line, it was expressed by Yan, and Roggema [34], for whom "design solutions will be transferred to action programs for the UN Sustainable Development Goals (SDGs) with the cooperation of producers that aim for the balance of beneficial economic effects and the environment, citizens in search of a better living environment, and governments that seek to provide efficient public services." Additionally, Pruneau et al. [35] showed DT's use by numerous leaders in sustainable development.

Design with users, design by users, or design for users is popularly advocated within areas such as innovation and product development [36,37]. However, how to sustainably involve stakeholders, especially over the long term, is not easy for any participatory project. Engaging citizens in design tasks is a difficult challenge.

In the case of urban water, there are multiple examples of DT and ULL use, including workshops to achieve citizen engagement in the public sphere of water management in the city, as mentioned in [34]. Of particular relevance is the case of the city of Doha (Qatar) in its project, The Urban Water Machine.

Service Design Thinking (SDT) or design for services emerges from DT, to develop innovative services tailored to customer needs as suggested [38,39]. According to Clatworthy [40], SDT is defined 
as: "Designed offerings to provide experiences that happen over time and across different touch-points." Clatworthy [40] continues delimiting that "the time aspect is described as a customer journey, and along this journey, the customer interacts with the touch-points of a service. Touch-points are often tangible or human, such as a building or a service assistant, but can also be intangible such as the smell of coffee at a coffee bar." That is, they can be from material artifacts, environments, or interpersonal encounters. They can originate both from the organization (internal) and the clients (external), and they can be before the purchase, during the purchase, or after it.

Therefore, SDT appears as an exploratory process that creates new types of value through the interrelation of different actors (value ecology [41]) within a socio-material configuration [42]. A vital relationship occurs between touch-points, value-created/value-in-use [43], and customer experience.

A customer can use different touch-points as part of their customer journey, in different combinations each time they use a service. Touch-points are where value is exchanged between the customer and the service company. Consequently, they are a critical part of the service design [40]. Touch-points are tangible evidence of services as part of what is called service blueprinting [44].

Therefore, service design is based on the choice of the most relevant touch-points. This opens a wide range for different opportunities for innovation through touch-points [45]:

1. Creating consistency across touch-points.

2. Introducing new touch-points.

3. Replacing touch-points.

4. Optimizing individual touch-points.

5. Expanding the service journey by adding touch-points at earlier or later phases of the journey.

In the case of SDT, the service provides an offering that is intangible and difficult to describe, and that is perceived and experienced before, during, and after using it. It is an extension of the brand, expressing benefits at the functional, emotional, self-expressive, and idealistic levels [39]. Trust is the central part of the service brand. There is a precise alignment between the offering and service brand.

The solution is designed with two perspectives: "a zoomed-out perspective (the offering) and a zoomed-in perspective (the interactions) to create the link between these, that is, between the high-level offering and the experience of use" [39]. This approach differentiates it from the traditional scientific approach based on deduction and induction. DT is "abductive, in the sense that it entails a divergent, broadening phase of unexpected idea gathering, followed by a convergent phase in which the most promising ideas are selected and put into practice ... abductive reasoning as an alternative approach that entails imagining what might be, rather than the analysis of what is, to create new knowledge and insights" [46].

The use of DT provides a systematic approach and a variety of techniques that can be adapted to the needs of the challenges to be solved [47]. All of them aim to achieve a deep understanding of the values, motivations, barriers, and behaviors of the users of a product or service. Observational techniques inspired or derived from anthropology and ethnography are also a differential characteristic of DT, which allows inferring the actual behavior of users. New ICT technologies (mobiles, websites, etc.) and social media that allow real-time interaction with the user are useful tools to infer such behavior, especially in those contexts and private spaces, such as the home, and they are excellent support for such observational techniques. In this way, a differential advantage can be achieved compared to other research techniques such as surveys or focus groups, where there can always be a gap between what the participants declare to do and the real behavior that they have in their daily situations [48].

The different types of design results that DT can produce can be categorized concerning the sustainability of the designed product or service [49]:

1. Eco-design: material efficiency, environmentally sustainable materials, efficiency in use, and design to allow recycling and durability/longevity.

2. Design for a purpose: that meets the needs of users. 
3. System design: design as a whole, taking into account the whole context, product service systems (PSS), design for organizations.

4. Design for behavior: design that influences user behavior towards more sustainable use.

In the first three types of results, DT reflects the user's behavior regarding the design of the product or service. The fourth type (design for behavior) is the design of the product or service that influences the user's behavior. The first three reflect either a market-pull approach or a technology-push approach, while the fourth reflects a design-push approach [50]. The latter "innovation where the novelty of message and design language are significant and prevalent compared to novelty of functionality and technology" [51]. In our case, to achieve greater engagement of households regarding the efficient use of water, it is necessary to generate new messages and meanings regarding water, acting in the semantic dimension, perhaps combined to a greater or lesser extent acting in the functional dimension (technology) around water [50].

We pretend to produce an innovation of meaning, a novel purpose, a new how, a new why, and a new perspective of what has meaning for people [46]. The market does not require new meanings, but they are gifted by organizations responsible for interpreting what is good and what is bad [46]. The goal is to create a radical vision, a new strategic direction that is powerful, robust, and meaningful.

This approach interprets humans as gift recipients. Meanings cannot be outsourced: while users can be particularly valuable in providing inspirations for new solutions, their contribution is less effective in supporting the development of new meanings. People are gifted by organizations with new meanings [46].

It should be noted that also of special interest is the type of design produced by PSS, which emphasizes a paradigm shift in the perception of wellbeing by the user, going from a design that produces a sense of wellbeing based on product ownership, to a design based on the freedom of access to the service that the good produces for the user (access-based wellbeing) [52]. The service provider is the owner of the products that facilitate such service. The interest in increasing the efficiency, durability, and reuse of the materials involved in its provision is aligned with the economic benefit of the service provider. Therefore, this model change produced by DT aligns PSS with sustainability.

As highlighted by Goodspeed et al. [53], the choice of available DT methods and their scope "can vary widely, since it depends on the complexity of the tool, availability of existing inputs, and availability and costs of technical and human resources. The most significant additional expense of the design methods is associated with the logistics of stakeholder participation, which may include travel, staff time to attend events and analyze the feedback, and staff time associated with other forms of stakeholder communication such as interviews, surveys, and emails. The hard costs of tool development-software, servers, and programming — are likely to be somewhat similar for either method, since most software is developed through iterative methods and similar technical skills are needed for both approaches."

\section{Materials and Methods}

This article presents a research proposal to verify the effectiveness of getting household engagement about urban water efficiency use, by combining two elements: methods/strategies of water demand management and facilitating technologies. All of these elements belong to the DT universe.

As highlighted [54], Horst Rittel already in 1960 underlined the usefulness of HSC methodologies to solve "wicked problems", understood as a class of social system problems that are ill-formulated, where the information is confusing, where there are many clients and decision-makers with conflicting values, and where the ramifications in the whole system are thoroughly confusing [55].

This type of HSC methodologies provides advantages over the typical purely scientific approach, based on inductive and deductive reasoning. In the scientific approach, problem-solvers are distanced from the object of study. However, when solving complex problems such as identifying climate change adaptation strategies, it is necessary to add another competence: abductive thinking, which consists of imagining things that could work. Design Thinking, during which the problem-solvers immerse 
themselves in the object of the study's environment, calls upon inductive, deductive, and abductive reasoning. It would be productive in situations where there is uncertainty [56].

We want to highlight that there are other methodologies that are not purely DT, but that place people as active agents that contribute decisively in making sustainability issues visible, as an important part of the community's agenda. This is the case of [12], which uses educational strategies by introducing content about water scarcity in Jordan in students' textbooks, to influence the perception that students and teachers have of this challenge. Textbooks are the tool of choice to make the water problem visible. This strategy also follows a principle of water demand management, which is completed with a follow-up through semi-structured interviews of how the students can lead their daily lives, aiming to change their behaviors in their water-related lifestyle. The objective was also to suggest that "students use water more efficiently and reduce the waste of water at the domestic level as well as in gardening and farming practices" [12]. In the latter case, the sphere of action is public. The proposal we make in this paper takes place in the private sphere, through the relationship established through the public water service between the water company and households.

The case of utility companies such as water, gas, or electricity presents a special complexity compared to other non-commodity industries [57]:

1. They cannot adjust the characteristics of the water, since it is a highly standardized product, as companies that manufacture a purely industrial product can.

2. They do not have many opportunities to generate engagement or have close or constant customer relationships (touch-points). In fact, they lack in-depth knowledge of their clients' needs to develop a more effective service.

Therefore, it seems clear that adopting a human-centered perspective, such as that provided by DT, can provide them with a variety of effective techniques to meet the needs of their clients. The prototype created using SDT can use, in different phases, complementary techniques such as service blueprints [58] to create process diagrams of the front-end and back-end activities necessary to provide the service. The method Service Blueprinting is the visualization of all touch-points and processes aligned to the user experience above and below the line of visibility to the user [30], but it is usually used in later stages of the innovation process.

The case of the Austrian gas company Redgas, a subsidiary of Linz AG, is an example of SDT's application to the case of a utility [57]. To achieve greater engagement from its customers, this company especially reviewed, among other things, the processes where the touch-points were produced with its customers through "service safaris" or "customer journey". This was part of the exploration stage within the SDT. Likewise, they paid particular attention to the website [59], seeking clarity, ease of use, trustworthiness, and attractive visualization, since the web allowed them to expand touch-points with their clients, and therefore, better opportunities to achieve greater engagement with them. Moreover, they reviewed other industries for solutions. In our case, we did the same, highlighting in our search the website of a local savings bank in Andalusia, Caja Rural del Sur, focused on the education of its customers in sustainability (especially in the calculation of the carbon footprint) [60].

DT has also been experimented with in smart cities initiatives in Brazilian cities [54] and South African cities [61]. Furthermore, particularly in the case of water management, it has been used for the development of water treatment and purification products and for the design of water management after environmental disasters [62]. Moreover, DT has been used through the support of ICT and social media, such as the use of tablets and Facebook, to locally manage by a community of women the problems derived from climate change that cause floods and poor water quality in Morocco [56]. This approach allowed them to improve their water consumption habits.

ICT and social media have been used within DT in several of its stages: "to share opinions and information about a situation (Stormboard, Narrative Clip); to summarize information (Popplet); to consult experts (Skype); to propose and comment on ideas (Padlet); to vote (choose among ideas, Loomio); to sketch prototypes (iDroo); to plan (Wrike); and, to communicate (Facebook, Glogster)" [63]. 
Here, we define "prototype" as anything that a user can interact with, stimulating discussion and facing problems from different perspectives. A prototype may be developed even when the problem is not yet well defined, getting stakeholders involved in the project development. The prototype allows for understanding the feasibility of an idea.

Furthermore, following the recommendations of Meyer and Tucker [64], in the case of Redgas, qualitative techniques were used, and 57 in-depth interviews were conducted with their clients to understand their needs and behavior better. With the conclusions of these interviews, they created four "people" that reflect the clustering of four customer segments, with distinctive needs, values, and behaviors.

In the creation stage, they generated three value propositions in the form of concepts or "service prototypes" with clear audiovisual content. These prototypes were made using simple mock-ups, not complex or elaborate, with a low-cost philosophy. In our case, in addition to collecting these experiences, we follow three principles [65]:

1. Fast: that it allowed a fast interaction and feedback.

2. Available: minimum, that only the idea to be communicated is expressed and nothing else.

3. Focused: focusing on the most important things to check.

In the reflection phase, they collected customer feedback, from the four people archetypes to the proposed prototypes. They used the technique of "storytelling" to explain these service prototypes through a compelling and clear narrative, through personal interviews and three focus group sessions. They also used "desktop walkthroughs" to check the web usability using prototypes made with PowerPoint.

Finally, in the implementation phase and with the lessons learned from the previous stages, they refined communication to clients, making it more effective. Communication became a crucial issue in order to achieve customer engagement. This argument led us, in our case, to hire for this project an agency specialized in digital marketing [66], to develop our visually more attractive "service prototypes" to achieve more effective communication.

In our case, to achieve higher engagement of households regarding the efficient use of water, it is necessary to generate new messages and meanings regarding water, acting in the semantic dimension, perhaps combined to a greater or lesser extent acting in the functional dimension (technology) around water [50]. In a way, we are approaching a radical design-driven innovation [67], since changing people's behavior is a very complex challenge, with interdependent habits and practices, as well as symbolic and functional factors that influence individual consumption patterns. It is the weight of the semantic dimension in our project that has led us to contract an agency specialized in web design to generate our prototype with which to interact with households (web-based prototype) [58], since the graphic part and the web customer relationship interface are critical. Wicked problems are too abstract; therefore, they are difficult to communicate with words. Having a good graphical interface is essential for the success of the project. Furthermore, as Dell' Era et al. [50] pointed out, "rather than investing in a few core technologies, design-driven companies need to investigate different technologies to propose new interpretations of product languages. Consequently, they need to form several collaborations and partnerships with external suppliers that manage different technologies."

There are three primary methodologies for encouraging behavior change through design [68]:

1. Scripts and behavior steering: products or systems that contain scripts or prescriptions that try to express the designer's intentions.

2. Eco-feedback: those methodologies inform users of their impact to try to persuade them to modify their behavior.

3. Intelligent products and systems: those methods that, to a greater or lesser degree, transfer the power of decision to an intelligent product that mitigates, controls, or blocks the behavior to be changed. 
In our case, for our research, we will use the three methodologies. For eco-feedback, "smiley faces" have been used effectively to represent energy consumption compared to existing social norms [69].

We have also proposed to use other HSC methodologies, such as gamification [19], to encourage and reward household engagement. Moreover, it is intended to work the part of trust, through the "service brand" [39]. Trust, together with the improvement of the sustainability challenge's understanding, is a critical factor in the educational activities carried out in other projects for its success [13]. Therefore, it seems clear that actions must be brought into play that improve the perception of the "service brand" by households to increase household trust in the proposed actions. Concrete actions will be designed to enhance the "Aguas de Huelva" brand through the web-based prototype as a method to increase the "service brand" among the households participating in the pilot.

Of the 172 DT methods identified [30], and following the s stages defined in the Stanford ME310 model [70] as shown in Figure 2, we have chosen the most relevant to our project that coincide with the most used according to the ranking for service companies [30]:

1. Define: we follow the "Desk Research" method, second in the ranking. Previous bibliographic review with similar experiences of "engagement" of homes in other parts of the world. We also follow "Trend research".

2. Needfinding:

a. To carry out the first prototype, we followed the interviewing method, first in the ranking of [30]. We conducted in-depth interviews with different specialists from the company Aguas de Huelva who gave us the vision of the utility: the director of innovation and social responsibility, the commercial director, and the general director. In addition, we sent surveys to households that agreed to participate in the experiments to allow them to know their needs, values, knowledge of the integral water cycle, and water use in the home.

b. For the refinement of this first prototype, that is, for the construction of the second, it is intended to use "Shadowing" through tracking on the use of the first web prototype and "Person" (through workshops).

3. Synthesis: we use the Clustering method, first in the ranking of [30]. Using the statistical analysis of the different sections of the survey responses, we tried to obtain different household profiles similar to those obtained in [4], based on knowledge of the integral water cycle, values, needs, and declared uses that households make water.

4. Ideation:

a. In the first phase, the brainstorming technique, second in the ranking [30], was used among experts from Aguas de Huelva, the Suez group, UPM (ourselves), and the web design agency. Given the importance of the visual and operational design of the web prototype in achieving household engagement, it was decided to directly hire a web design agency specialized in the subject [65] and with previous experience in sustainability issues [59]. They directly designed and implemented the prototype.

b. In a second phase, with feedback from households and traceability data on the use of the first prototype, the objective is to build the second prototype directly by the web design agency.

5. Prototyping:

a. Given the costs and the speed with which the first prototype was to be implemented, it was decided, as we said in the previous point, to hire a specialized web design agency. The proposal includes sending emails with links to a landing page (web) that allows us to immerse themselves in the context of households in their daily activities, "without the observer influencing them and collecting information from both their actions such as humor, body language, rhythm or action times, achieving a total image of the world from 
the user's point of view" [62]. This technique with the different household profiles is called "shadowing," and it seemed to us the most appropriate to evaluate the effectiveness and impact of the proposed prototype in the day-to-day life of households.

b. As mentioned in the previous point, the construction of a second prototype by the web marketing agency is planned.

6. Testing: we will use the first two techniques of the ranking [30], "Feedback Capture Grip" (through workshops), and "Usability Testing".

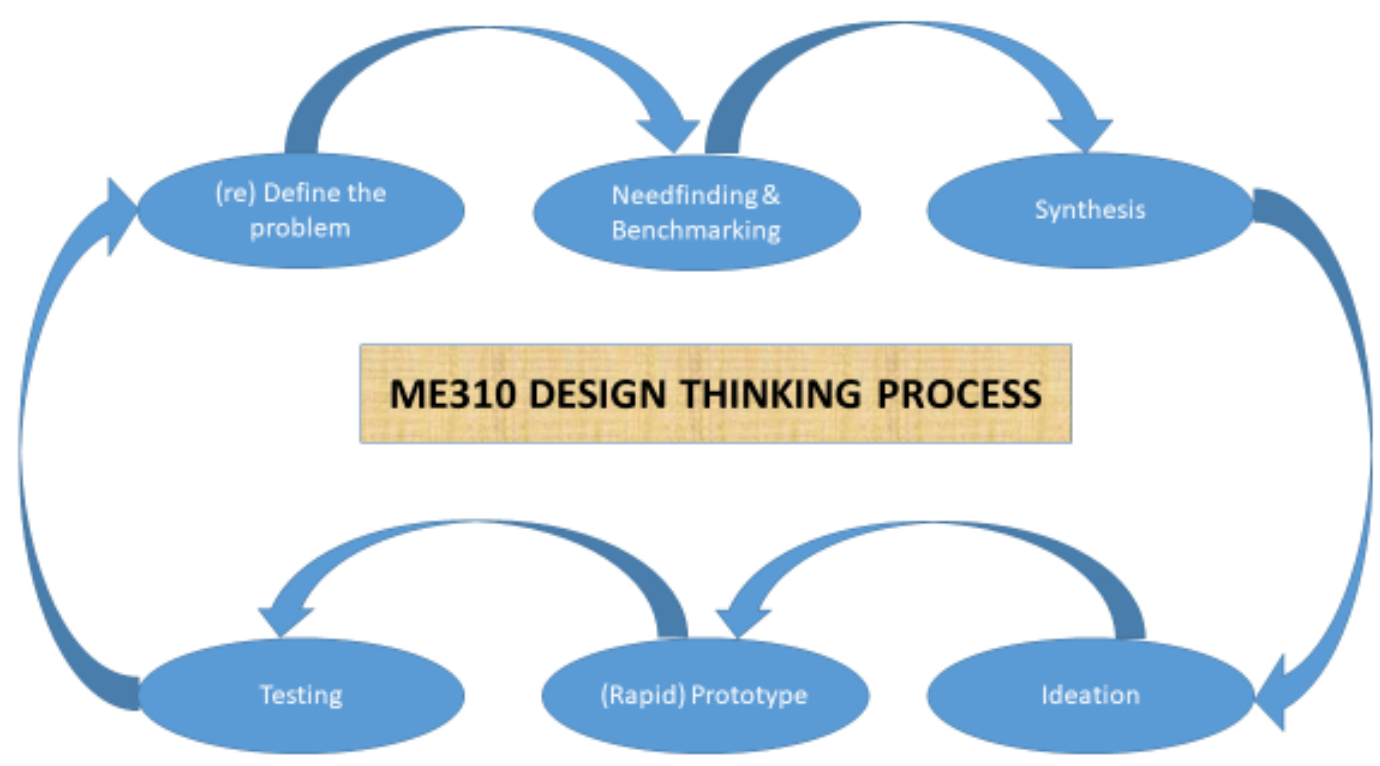

Figure 2. Stanford ME310 model. Adapted from [70].

Details of most of the 172 methods can be accessed in [71]. Among them, the workshops are described. The workshops that are intended to be articulated with the participation of households will be based on a structure like the one proposed [53]:

1. Welcome and introductions.

2. Icebreaker activity to warm up participants.

3. Project overview: explanation of the scope, structure, and objectives of the project.

4. Brainstorming exercise: proposals for improvement of the web-based prototype.

5. Idea voting: the selection of the improvements to introduce.

6. Tool concept development: preliminary graphic design of the improvements to be introduced.

7. Report-out and discussion: summary and selection of households interested in participating in future developments.

As proposed in [53], the workshops' validity will depend on the results achieved through the web-based prototype, based on the relationships established between the different dimensions of the workshop framework, as shown in Figure 3. 


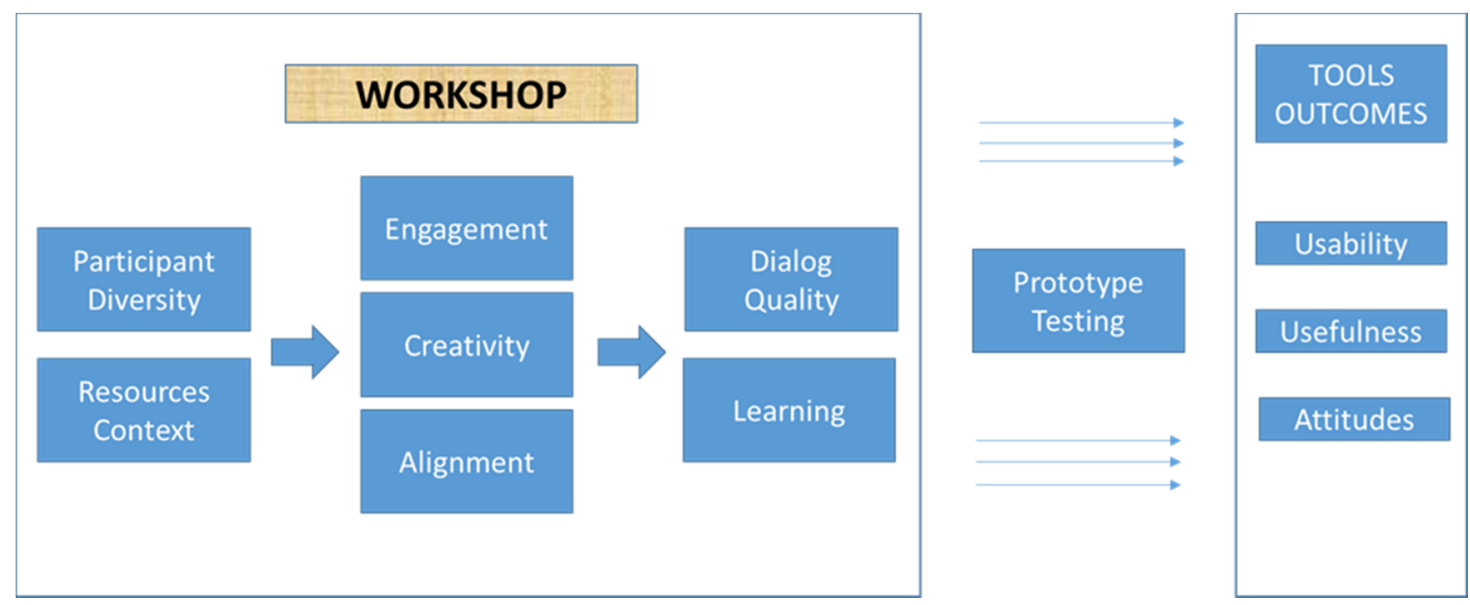

Figure 3. Workshop Framework Dimensions. Adapted from [53].

\section{Results}

From the Food Quality Engineering Research Group (ETSII-UPM), we responded to the challenge for a more efficient and sustainable use of water in homes, which the Suez group defined through the UP4 Solutions program, in collaboration with the UP4 technological universities alliance (Universitat Politècnica de Catalunya, Universidad Politécnica de Madrid, Universitat Politècnica de València, Universidad Politécnica de Cartagena) [72].

In this section, we describe this challenge to which we responded and which, as a result, gave rise to the framework presented based on DT methodologies, approved by the Suez group to be carried out in its investee company "Aguas de Huelva". This section is intended to show some results and milestones achieved in this project.

The main objective of the challenge is to promote the efficient and sustainable use of water resources based on information, communication, and awareness of citizens. The project focuses on understanding, within the water cycle, what are the factors, elements, and data that generate the most significant impact and understanding of the challenges faced in terms of water resource management, thus, being able to generate a reflection of households towards a cultural change regarding their use and valorization. For this, within the project, the following specific objectives have been defined:

1. Evaluate the degree of knowledge of consumers about the challenges associated with the sustainable use of water.

2. Identify their needs as consumers.

3. Determine and prototype solutions that help raise awareness and value water use sustainability, proposing specific actions to consumers that address part of their needs at the same time.

These objectives should help to directly relate the day-to-day behavior of Huelva's households with the sustainability of comprehensive water management. In this way, it is intended to promote a change in consumer behavior, which, together with the efforts of the managers of the urban water cycle (Aguas de Huelva), should lead to more sustainable use and better protection of current and future resources.

Changing people's behavior is a complex challenge, with interdependent habits and practices, as well as symbolic and functional factors that influence individual consumption patterns. The aim is to calibrate the goodness of the extent to which it is possible to change habits or instead aspire to achieve more efficient water use without changing households' private daily lives.

The Suez group designated Aguas de Huelva, a company in which the group participates, as the utility to carry out the project in the city of Huelva. The city of Huelva has approximately 140,000 inhabitants. The utility Aguas de Huelva has around 52,000 customers, mainly households. 
These customers are distributed in six districts that show social homogeneity. Of the 52,000 customers, 9350 of them received a digital invoice, from which it can be deduced that they are accustomed to using ICT technology tools, such as email, SMS, APPs, and web browsing and have sufficient technological infrastructure (computers, tablets, smartphones, and telecommunications connectivity) to communicate with them through digital channels.

To carry out the project, we designed a response plan based on the DT methodology with the elements described in the previous sections of this article. The Suez group and Aguas de Huelva approved the implementation of this plan, within a time horizon of one year, to avoid the seasonal effect of the natural water cycle in Spain. We defined a goal with a sample of households in a range between 200 and 300 households. The participating households were selected at random, following the stratified sampling technique among the 9350 clients who received a digital invoice, trying to have a representative sample from each of the six sectors of the city, although a priori there were no social differences between households in these sectors. This factor was crucial since the web-based prototype required that the home have a basic ICT infrastructure and be able to receive emails. Moreover, since most households did not have smart meters, too, an attempt was made to have a representative sample of those who did have smart meters. In this way, we ensured in the testing phase that we could measure the influence of giving information in quasi-real-time on consumption to households with smart meters and check the differences in response to the stimulus frequency, compared to households that did not have a smart meter. Households without Smart meters had greater logistical complexity, since they required sending field technicians to do manual meter readings in each of the participating households, every fortnight, which conditioned the frequency of sending information to those households. Therefore, an attempt was made to balance the randomness required in this type of experimentation with logistical, budgetary, management, and time limitations, that do not condition the validity of the framework approved by Aguas de Suez.

This plan was approved in July 2018. The plan contemplates three phases:

1. The measurement of the starting point of households in Huelva regarding the three axes of knowledge, needs, and valuation of water.

2. Proposal for a web-based prototype to measure the impact of actions in the three previous axes (touch-points with households) to increase engagement regarding water.

3. Workshops with households to qualitatively measure their evaluation of the prototype and possible improvements to incorporate into a new prototype, the last one, before the final launch of the web-based solution.

In summary, the plan contemplates a first phase that corresponds to a study of the knowledge that households have of the integral water cycle and of the values and relationship that they have concerning water. These parameters will be measured through a survey, with questions/answers that will follow a five-point Likert scale, associating them with three major factor blocks:

1. Demographic characteristics.

2. Home characteristics.

3. Life experiences and psychosocial factors.

The positive or negative attitudes that households have regarding:

1. Support for alternative sources of water.

2. Pro-environmental attitude: the environmental identity of the home.

A survey with 29 questions was prepared, together with experts from Aguas de Huelva, divided according to the objectives to be measured and the factor blocks. The idea was to have it answered in about $30 \mathrm{~min}$. The survey questions were also reviewed, again, by 15 experts from Aguas de Huelva, making various modifications and eliminating some of the original questions proposed by the UPM 
team. This was done during September 2018. The means to make it reach the citizen would be through email with a link to Aguas de Huelva web site where the survey is placed.

The commitment of participation of 120 households was achieved. In December 2018, the survey was launched via email with a link to questions to the 120 participating households. Finally, in mid-June 2019 , after several rounds of survey submissions, the survey response collection process was closed with a total of 97 valid responses from participating households.

Surveys have been statistically processed using IBM SPSS v. 25, but the analysis of the results exceeds the purpose of this article and will remain for future publications. As a summary, regarding the mathematical analysis of the data, Dean et al. [4] have proposed the use of statistical classification techniques (clustering) to detect groupings of households with similar patterns of needs, values, and behaviors. This approach allows directing more effective concrete messages to each group, both during the experiments, as well as in the post-research phases, and lessons learned to be implemented.

This type of grouping of households will make it possible to direct strategies for managing demand and the commitment of citizens to water, which are more effective in today's cities, characterized by having very dynamic societies, made up of citizens who have a significant difference and variety of knowledge, values, and behaviors. These would be targeted strategies, more differentiated, and better built according to the households. Such strategies can be facilitated by scaling the research pilot to all homes in the city, using techniques and technologies of Artificial Intelligence (AI) and Big Data, such as machine learning and Artificial Neural Networks (ANN). We will follow this methodology [4] to cluster households, as stated in one of the DT methods.

In the second phase, where we are currently, we are proceeding to design the web-based prototype, which will be the means to increase the touch-points with households through different experiments that allow us to interact with households to measure consumption habits and the possibility of varying or changing them, towards a more sustained use of water. These experiments will be oriented with information tailored to each of the clusters obtained to vary their behavior and achieve higher engagement by increasing the knowledge capital and the accumulated wealth of households [3].

Supporting the web-based prototype, we will use ICT facilitators, as communication and information tools with households:

1. Smart meters, if available, or failing that, manual readings of the existing meters. It will try to measure, from the point of view of household management, how effective this tool is, given the cost of its deployment. An interesting study that reviews the state of said technology can be found in [73].

2. Email as a communication channel with the client.

3. Software such as APPs for mobile phones that allow better interaction and better quality of information with the homes.

Finally, the timing of this second phase, where we will interact with households, has been reduced to three months, due to the current coronavirus pandemic that the world is suffering. It is expected to be launched in September, October, and November 2020.

The third phase, that of the workshops with the participating households, to refine the "web-based" prototype using qualitative information, is scheduled to be carried out in December 2020 once sufficient quantitative information has been obtained by tracing the actual use of the web-based prototype by households.

\section{Discussion}

One of the issues that we want to point out as a possible point of discussion is the role of ICT as facilitators of household engagement regarding sustainability in the use of urban water. As indicated in [56], there are enough experiences that point to the power of these technological tools. "However, this research reinforces the idea promoted by the International Telecommunication Union (2015): ICTs could facilitate the achievement of the Sustainable Development Goals (SDGs). They could empower 
people, particularly women, by reinforcing their capacities to solve their problems and to resist climate change. Facebook is potentially beneficial for interaction, collaboration, information, resource sharing, and problem-solving. Future research should focus on discovering ways to leverage Facebook for other uses linked to problem-solving with DT: summarizing information, consulting experts, voting (choosing among different ideas), and planning tangible on-site adaptation strategies. To increase creativity, other online brainstorming tools (Padlet, Popplet, Mind 42, or Loomio) might be used favorably in solving environmental problems, which was not possible in the current research given the novice ICT abilities of our participants" [56].

We also want to highlight that the project's timing has been reduced to three months compared to what was originally intended (one year). This reduction has been due to the fact that, as is well known, the scope of the projects depends on multiple factors such as the client's budget, time, and confidentiality agreements. This may condition the depth of the results obtained, since "Similarly, evaluation of implementation efforts from a short-term perspective can result in their being considered a failure as many intended effects are realized in the long-term. Design Thinking requires time, space, and authorization to operate" [13]. Additionally, "The effectiveness of Design Thinking will depend on the users' understanding and intent. It is a time-consuming process and should not be undertaken for gains in efficiency" [13].

This is in line with what is suggested in other articles such as [12], where strategies of empowering citizens to become actors of change and modifying their daily water use habits require long-term focus and sustained effort. In this sense, and as part of the empowering people strategy, [13] highlights citizenship education as a tool and a long-term process. However, as the short-term suggests [13], concrete benefits for citizens are essential to get engagement. This is what is pursued with the proposal of this paper: demonstrate short-term benefits to households through the use of the web-based prototype that increases household engagement regarding the more efficient use of water in them. In any case, the project's duration is a factor to reflect on, a challenge to be resolved between the long-term or short-term focus to be more effective in household engagement.

On the other hand, it must be taken into account that a compromise must be reached between the fidelity of the final design, investment, time, and other factors and that, therefore, the result of the web-based prototype that we obtain is not a market-ready service product. "Once the Design Thinking phase has been completed, the interactive dynamic between users and the design for the most part ends. The design outcome provides an established set of user-facing requirements that need to be implemented and tested to accepted production quality. Given the speed at which prototype code is written, its base may only be partially salvageable. The languages and libraries chosen may have enabled prototyping speed and flexibility. Now knowing what needs to be implemented, the language and library selections may need to be revisited to provide a more manageable, reliable, secure, and computationally efficient foundation" [74]. At any rate, given that in this case, it is a web-based prototype, it is expected that it will be relatively easy and quick to develop it as a final service.

Additionally, we want to point out the limitations regarding the number of participating households, since, as indicated [74], "Design Thinking does not mitigate all the risk of innovation. At times it may appear to make innovation riskier. Locating restless users for your cooperating user pool may not be easy; however, they are extremely helpful. Regular users are needed, as well. A challenge is to find a diverse set of restless users." However, with the participation of the 105 households that have accepted the invitation to participate in the experiments, we believe that this last point has been achieved, by minimizing the effect of uncertainty, the personal preferences of each household, the possible errors in obtaining household data, misunderstandings in language and communication with households, and inconsistencies, among other. In any case, the experience can be scaled in the future to all households in Huelva, using different ICT solutions, such as Big Data techniques and inference of future behaviors of homes such as through Artificial Intelligence.

Moreover, "user experience" should not be confused with "usability", since the first "is not limited only to improving performance in the product-user interaction, but seeks to systemically solve the 
strategic problems of product utility, the psychology of pleasure and satisfaction of use" [25]. DT covers the end-to-end experience, from the organization of the elements and processes of the organization that provides the service (or manufactures the product) to the user experience when it benefits from the value provided by the organization.

Finally, we want to point out that the conclusions of the 97 valid results of the statistical processing of the surveys, as well as the statistical clustering of households, will be published in future articles, as they exceed the scope of this article.

Author Contributions: Both authors participated directly in this research. G.B.-M. as a doctoral student in Industrial Management gathered and processed the relevant data and wrote the original draft. C.R.-M., as thesis director, designed and supervised the research project. All authors have read and agreed to the published version of the manuscript.

Funding: This research received no external funding.

Acknowledgments: This study was partly supported by the Suez group and Aguas de Huelva.

Conflicts of Interest: The authors declare that they have no conflict of interest.

\section{Abbreviations}

$\begin{array}{ll}\text { AI } & \text { Artificial Intelligence } \\ \text { ANN } & \text { Artificial Neural Networks } \\ \text { CSR } & \text { Corporate Social Responsibility } \\ \text { DT } & \text { Design Thinking } \\ \text { ETSII } & \text { Escuela Técnica Superior de Ingenieros Industriales } \\ \text { HSC } & \text { Human Smart Cities. } \\ \text { ICT } & \text { Information and Communication Technologies } \\ \text { ISUDS } & \text { Integrated Sustainable Urban Development Strategy } \\ \text { PSS } & \text { Product Service Systems } \\ \text { SDG } & \text { Sustainable Development Goals } \\ \text { SDT } & \text { Service Design Thinking } \\ \text { SUWM } & \text { Sustainable Urban Water Management } \\ \text { ULL } & \text { Urban Living Labs } \\ \text { UP4 } & \text { Network of Spanish Technical Universities } \\ \text { UPA } & \text { Urban and Peri-urban Agriculture } \\ \text { UPM } & \text { Universidad Politécnica de Madrid } \\ \text { WSC } & \text { Water Sensitive City }\end{array}$

\section{References}

1. Bermejo-Martín, G.; Rodríguez-Monroy, C. Sustainability and Water Sensitive Cities: Analysis for Intermediary Cities in Andalusia. Sustainability 2019, 11, 4677. [CrossRef]

2. Alderfer, C.P. An empirical test of a new theory of human needs. Organ. Behav. Hum. Perform. 1969, 4, 142-175. [CrossRef]

3. Strengers, Y. Smart Metering Demand Management Programs: Challenging the Comfort and Cleanliness Habitus of Households. In Proceedings of the 20th Australasian Conference on Computer-Human Interaction: Designing for Habitus and Habitat, Cairns, Australia, 8-12 December 2008; pp. 9-16.

4. Dean, A.J.; Lindsay, J.; Fielding, K.S.; Smith, L.D.G. Fostering water sensitive citizenship-Community profiles of engagement in water-related issues. Environ. Sci. Policy 2016, 55, 238-247. [CrossRef]

5. De Haan, F.J.; Ferguson, B.C.; Adamowicz, R.C.; Johnstone, P.; Brown, R.R.; Wong, T.H.F. The needs of society: A new understanding of transitions, sustainability and liveability. Technol. Forecast. Soc. Chang. 2014, 85, 121-132. [CrossRef]

6. Chefchaouen Declaration-Charter of the Intermediary Cities of the World. In Proceedings of the 1st World Forum Intermediary Cities, Chefchaouen, Morocco, 25 July 2018; Available online: https://intermediarycities.uclg.org/sites/intermediarycities.uclg.org/files/2018-07/EN_Declaration\% 20Charter\%20of\%20Intermediary\%20Cities\%20of\%20the\%20World.pdf (accessed on 28 June 2020). 
7. Martinez, P.; Blanco, M.; Castro-Campos, B. TheWater-Energy-Food Nexus: A Fuzzy-Cognitive Mapping Approach to Support Nexus-Compliant Policies in Andalusia (Spain). Water 2018, 10, 664. [CrossRef]

8. Buerkert, A.; Schlecht, E. Rural-urban transformation: A key challenge of the 21st century. Nutr. Cycl. Agroecosyst. 2019, 115, 137-142. [CrossRef]

9. Riad, P.; Graefe, S.; Hussein, H.; Buerkert, A. Landscape transformation processes in two large and two small cities in Egypt and Jordan over the last five decades using remote sensing data. Landsc. Urban Plan. 2020, 197, 103766.

10. Wong, T.; Brown, R.R. Transitioning to Water Sensitive Cities: Ensuring Resilience through a new Hydro-Social Contract. In Conference Proceedings: 11th International Conference on Urban Drainage (pp. CD Rom - CD Rom); Ashley, R., Ed.; Iwa Publishing: Edinburgh, UK, 2008.

11. Fletcher, T.D.; Shuster, W.; Hunt, W.F.; Ashley, R.; Butler, D.; Arthur, S.; Trowsdale, S.; Barraud, S.; Semadeni-Davies, A.; Bertrand-Krajewski, J.L.; et al. SUDS, LID, BMPs, WSUD and more-The evolution and application of terminology surrounding urban drainage. Rev. Urban Water J. 2014, 12, 7.

12. Hussein, H. A critique of water scarcity discourses in educational policy and textbooks in Jordan. J. Environ. Educ. 2018, 49, 260-271. [CrossRef]

13. Ide, T.; Tubi, A. Education and environmental peacebuilding: Insights from three projects in Israel and Palestine. Ann. Am. Assoc. Geogr. 2020, 110, 1-17. [CrossRef]

14. Veenhoven, R. Happy life-expectancy. Soc. Indic. Res. 1996, 39, 1-58. [CrossRef]

15. Brundtland, G.H. World Commission on Environment and Development (WCED). Our Common Future 1987, $17,1-91$.

16. Oliveira, Á.; Campolargo, M. From smart cities to human smart cities. In Proceedings of the 48th Hawaii International Conference on System Sciences (HICSS), Kauai, HI, USA, 5-8 January 2015; pp. 2336-2344.

17. Kumar, A.; Lodha, D.; Mahalingam, A.; Prasad, V.; Sahasranaman, A. Using' Design Thinking' to enhance urban re-development: A case study from India. Eng. Proj. Organ. J. 2016, 1-11. [CrossRef]

18. IDEO. Human-Centered Design Toolkit. 2015. Available online: https://www.ideo.com/post/design-kit/ (accessed on 14 May 2020).

19. Oliveira, Á.; Campolargo, M.; Martins, M. Human smart cities: A human-centric model aiming at the wellbeing and quality of life of citizens. In Proceedings of the eChallenges e-2014, 2014 Conference, Belfast, UK, 29-31 October 2014; pp. 1-8.

20. Aguas de Huelva. Available online: https://www.aguashuelva.com/-/retos-sociales-retos-compartidos/ (accessed on 14 May 2020). (In Spanish).

21. Mintrom, M.; Thomas, M. Improving commissioning through Design Thinking. Policy Des. Pract. 2019. [CrossRef]

22. Mintrom, M.; Luetjens, J. Design Thinking in Policymaking Processes: Opportunities and Challenges. Aust. J. Public Adm. 2016, 75, 391-402. [CrossRef]

23. Mintrom, M.; Luetjens, J. Creating Public Value: Tightening Connections between Policy Design and Public Management. Policy Stud. J. 2017, 45, 170-190. [CrossRef]

24. Altuna, N.; Contri, A.M.; Dell'Era, C.; Frattini, F.; Maccarrone, P. Managing social innovation in for-profit organizations: The case of Intesa Sanpaolo. Eur. J. Innov. Manag. 2015, 18, 258-280. [CrossRef]

25. Del Giorgio Solfa, F.; Amendolaggine, G.; Alvarado Wall, T.A. Nuevos paradigmas para el diseño de productos. Design Thinking, Service Design y experiencia usuario. Arte Investig. 2018, e012. [CrossRef]

26. Hila Shapira, H.; Ketchie, A.; Nehe, M. The integration of Design Thinking and Strategic Sustainable Development. Blekinge Institute of Technology, 37179 Karlskrona, Sweden. J. Clean. Prod. 2017, 140, 277-287. [CrossRef]

27. The Double Diamond: A Universally Accepted Depiction of the Design Process. Available online: https://www.designcouncil.org.uk/news-opinion/double-diamond-universally-accepted-depictiondesign-process/ (accessed on 14 May 2020).

28. Doorley, S.; Holcomb, S.; Kliebahn, P.; Segovia, K.; Utley, J. Design Thinking Bootleg; Hasso Plattner Institute of Design at Stanford: Stanford, CA, USA, 2018.

29. Liedtka, J.; Ogilvie, T. Designing for Growth: A Design Thinking Tool Kit for Managers; Columbia University Press: New York, NY, USA, 2011. 
30. Hehn, J.; Uebernickel, F.; Herterich, M. “Design Thinking Methods for Service Innovation—A Delphi Study -" (2018). PACIS 2018 Proceedings. 126. Available online: https://aisel.aisnet.org/pacis2018/126 (accessed on 14 May 2020).

31. IDEO. Design Thinking for Educators' Toolkit. 2012. Available online: http://designthinkingforeducators.com (accessed on 14 May 2020).

32. Brown, T.; Wyatt, J. Design thinking for social innovation. Dev. Outreach 2010, 12, 29-43. [CrossRef]

33. Brown, T. Design Thinking. Harv. Bus. Rev. 2008, 86, 84 .

34. Yan, W.; Roggema, R. Developing a Design-Led Approach for the Food-Energy-Water Nexus in Cities. Urban Plan. 2019, 4, 123-138. [CrossRef]

35. Pruneau, D.; Lang, M.; Kerry, J.; Langis, J.; Fortin, G.; Liboiron, L. Leaders of sustainable development projects: Resources used and lessons learned in a context of environmental education. J. Educ. Sustain. Dev. 2014, 8, 155-169. [CrossRef]

36. Bjögvinsson, E.; Ehn, P.; Hillgren, P. Design things and design thinking: Contemporary participatory design challenges. Technology 2012, 28, 101-116. [CrossRef]

37. Wahl, D.C.; Baxter, S. The designer's role in facilitating sustainable solutions. Des. Issues 2008, $24,72-83$. [CrossRef]

38. Wetter-Edman, K.; Snagiorgi, D.; Edvardsson, B.; Holmlid, S.; Grönroos, C.; Mattelmäki, T. Design for value co-creation: Exploring synergies between design for service and service logic. Serv. Sci. 2014, 6, 106-121. [CrossRef]

39. Lüders, M.; Andreassen, T.W.; Clatworthy, S.; Hillestad, T. (Eds.) Chapter 11: Service Design Thinking. In Innovating for Trust; Edward Elgar Publishing: Cheltenham, UK, 2017.

40. Clatworthy, S. Bridging the gap between brand strategy and customer experience. Manag. Serv. Qual. 2012, 22, 108-127. [CrossRef]

41. Vargo, S.; Lusch, R. Evolving to a new dominant logic of marketing. J. Mark. 2004, 68, 1-17. [CrossRef]

42. Kimbell, L. Designing for service as one way of designing services. Int. J. Des. 2011, 5, 41-52.

43. Sandström, S.; Edvardsson, B.; Kristensson, P.; Magnusson, P. Value in use through service experience. Manag. Serv. Qual. 2008, 18, 112-126. [CrossRef]

44. Shostack, L. Designing services that deliver. Harv. Bus. Rev. 1984, 62, 39-133.

45. Clatworthy, S. Service innovation through touch-points: Development of an innovation toolkit for the first stages of New Service Development. Int. J. Des. 2011, 5, 15-28.

46. Dell' Era, C.; Magistretti, S.; Cautela, C.; Verganti, R.; Zurlo, F. Four kinds of design thinking: From ideating to making, engaging, and criticizing. Creat. Innov. Manag. 2020, 1-21. [CrossRef]

47. Sato, S. Beyond good: Great innovations through design. J. Bus. Strategy 2009, 30, 40-49. [CrossRef]

48. Visser, F.S.; Stappers, P.J.; Lugt, R.V.d. Contextmapping: Experiences from practice. CoDesign Int. J. CoCreation Des. Arts 2005, 1, 119-149. [CrossRef]

49. Grant Young, Design Thinking and Sustainability. Available online: https://zum.io/wp-content/uploads/ 2010/06/Design-thinking-and-sustainability.pdf/ (accessed on 14 May 2020).

50. Dell' Era, C.; Marchesi, A.; Roberto Verganti, R. Mastering Technologies in Design-Driven Innovation. Res. Technol. Manag. 2010, 53, 12-23. [CrossRef]

51. Verganti, R. Design, Meanings, and Radical Innovation: A Metamodel and a Research Agenda. J. Prod. Innov. Manag. 2008, 25, 434-456. [CrossRef]

52. Manzini, E. Context-based wellbeing and the concept of regenerative solution: A conceptual framework for scenario building and sustainable solutions development. J. Sustain. Prod. Des. 2002, 2, 141-148. [CrossRef]

53. Goodspeed, R.; Riseng, C.; Wehrly, K.; Yin, W.; Mason, L.; Schoenfeldt, B. Applying design thinking methods to ecosystem management tools: Creating the Great Lakes Aquatic Habitat Explorer. Mar. Policy 2016, 69, 134-145. [CrossRef]

54. Depiné, Á.; de Azevedo, I.S.C.; Santos, V.C.; Eleutheriou, C.S.T. Smart Cities and Design Thinking: Sustainable development from the citizen's perspective. In Proceedings of the February 2017 Conference: IV Regional Planning Conference, Aveiro, Portugal, 23-24 February 2017.

55. Buchanan, R. Wicked problems in design thinking. Des. Issues 1992, 8, 5-21. [CrossRef]

56. Pruneau, D.; El Jai, B.; Khattabi, A.; Benbrahim, S.; Langis, J. Using design thinking and Facebook to accompany women in solving water problems in Morocco. In Handbook of Sustainability Science and Research; World Sustainability Series; Filho, W., Ed.; Springer: Berlin, Germany, 2018. 
57. Rau, C.; Zbiek, A.; Jonas, J.M. Creating competitive advantage from services. Res. Technol. Manag. 2017, 60, 48-56. [CrossRef]

58. Collaborative Service Blueprinting for Design Thinking: Evaluation of a Digital Prototype Tobias Potthoff1, Dominik Siemon2, Konstantin Wilms1, Sascha Möser2, Marco Hellmann1, Stefan Stieglitz1, Susanne Robra-Bissantz2. In Proceedings of the 51st Hawaii International Conference on System Sciences, Waikoloa Village, HI, USA, 3-6 January 2018; Available online: http://hdl.handle.net/10125/50467 (accessed on 14 May 2020).

59. Redgas. Available online: www.redgas.at (accessed on 14 May 2020). (In German).

60. Caja Rural del Sur. Available online: http://crsurcorazonverde.com/ (accessed on 14 May 2020). (In Spanish).

61. Van Waas, R.P. Designing an Integrative Approach to Regional Water Schemes in South Africa. Ph.D. Thesis, TU Delft, Delft University of Technology, Delft, The Netherlands, 2015.

62. Blanco, T.; Casas, R.; Asensio, A.; Tamargo, A. Diseño de la gestión del ciclo del agua en pequeños núcleos urbanos mediante Design Thinking. Dyna 2018, 93, 114-119.

63. Pruneau, D.; Langis, J. Design Thinking and ICT to create sustainable development actions. In Proceedings of the 7th International Conference on Computer Supported Education, Lisboa, Portugal, 23-25 May 2015; Volume 1, pp. 442-446.

64. Meyer, M.H.; Tucker, M.J. Innovating for effectiveness: Lessons from design firms. Res. Technol. Manag. 2010, 53, 21-28. [CrossRef]

65. Available online: https://medium.com/capitalonedesign/service-design-tools-methods-6e7f62fcf881 (accessed on 14 May 2020).

66. Enfoque Comunicación. Available online: www.enfoquecomunicacion.com/ (accessed on 14 May 2020). (In Spanish).

67. Verganti, R. Design as brokering of languages: The role of designers in the innovation strategy of Italian firms. Des. Manag. J. 2003, 3, 34-42.

68. Lilley, D.; Lofthouse, V.; Bhamra, T. Towards instinctive sustainable product use. In Proceedings of the 2nd International Conference: Sustainability Creating the Culture, Aberdeen, UK, 2-4 November 2005.

69. Schultz, P.W.; Nolan, J.M.; Cialdini, R.B.; Goldstein, N.J.; Griskevicius, V. The Constructive, Destructive, and Reconstructive Power of Social Norms. Psychol. Sci. 2007, 18, 429-434. [CrossRef] [PubMed]

70. ME310. ME310 Design Innovation at Stanford University. 2010. Available online: https://web.stanford.edu/ group/me310/me310_2016/ (accessed on 14 May 2020).

71. Available online: https://dschool.stanford.edu/resources/the-bootcamp-bootleg/ (accessed on 14 May 2020).

72. Available online: http://i2t.webs.upv.es/documentos/Reto2SUEZ.pdf (accessed on 14 May 2020). (In Spanish).

73. Boyle, T.; Giurco, D.; Mukheibir, P.; Liu, A.; Moy, C.; White, S.; Stewart, R. Intelligent Metering for Urban Water: A Review. Water 2013, 5, 1052-1081. [CrossRef]

74. Tannian, M.F. Embracing Quality with Design Thinking. In The Future of Software Quality Assurance; Goericke, S., Ed.; Springer: Cham, Switzerland, 2020; pp. 161-174. [CrossRef] 